\title{
As narrativas da Comunicação Organizacional da empresa de ERP - estudo de caso SAP
}

Ana Lúcia de Alcântara Oshiro

- Mestre em Comunicação Social pelo Programa de Pós-Graduação em Comunicação, Tecnologia e Mercado da Faculdade Casper Líbero

- Especialista em Comunicação e Marketing pelo Programa de Pós-Graduação da Faculdade Cásper Líbero

- Bacharel em Jornalismo pela Faculdades Integradas Alcântara Machado (FIAM)

- Diretora geral e fundadora da Tática Comunicação

- Professora do curso de pós-graduação MBA em Comunicação Corporativa e Gestão de Pessoas da Universidade Anhembi Morumbi

- ala.oshiro@hotmail.com

- oshiro.alcantara@taticacom.com.br 
Resumo

Este artigo analisa as narrativas do discurso informativo de reputação da comunicação organizacional da indústria de sistemas de gestão integrada ou ERP (Enterprise Resource Planning), tendo como estudo de caso a empresa global SAP. Este discurso embute em suas narrativas os conceitos da economia informacional de Manuel Castells e de rede, de Shapiro e Varian - que foram assumidos pelo pesquisador como valores informacionais do ERP. Como referencial teórico dos indicadores de reputação das narrativas analisadas, tomouse por base o estudo desenvolvido por Morten Thanning Vendelo (1998), além dos indicadores da reputação da comunicação organizacional presentes no estudo de Norberto Minguéz (1999).

PALAVRAS-CHAVE: REPUTAÇÃO • INFORMACIONAL • COMUNICAÇÃO ORGANIZACIONAL • SISTEMAS dE GESTÃO

INTEGRADA • ERP

Abstract

This article examines the narrative of the informative discourse of the reputation of the organizational communication of the integrated management systems industry, or ERP (Enterprise Resource Planning), with a case study of the global company SAP. This discourse has embedded in its narratives of the concepts of information economics of Manuel Castells, and of information network economics of Karl Shapiro and Varian - which were assumed by the researcher as ERP information values. A study conducted by Morten Thanning Vendelo (1998) was used as the base for a theoretical referential for the reputation indicators of the narratives analyzed: "Narrating corporate reputation: becoming legitimate through storytelling."

KEYWORDS: REPUTATION • INFORMATION • ORGANIZATIONAL COMMUNICATION • INTEGRATED MANAGEMENT

SYSTEMS • ERP

Resumen

Se analizan las narrativas del discurso informativo de reputación de la comunicación organizacional de la industria de los sistemas de gestión integrada o ERP (Enterprise Resource Planning), tomando como estudio de caso la empresa global SAP. Este discurso embute en sus narrativas los conceptos de economía informacional de Manuel Castells y de red, de Shapiro y Varian, que fueron asumidos por el investigador como valores informativos del ERP. Como referencial teórico de los indicadores de reputación de las narrativas analizadas, se tomó por base el estudio desarrollado por Morten Thanning Vendelo (1998), además de los indicadores de la reputación de la comunicación organizacional presentes en el estudio de Norberto Minguéz (1999).

PALABRAS CLAVE: REPUTACIÓN • INFORMACIONAL • COMUNICACIÓN ORGANIZACIONAL • SISTEMAS DE GESTIÓN

INTEGRADA • ERP 
Enquanto muitas das tecnologias tornam-se commodities, outras novas tecnoClogias surgem e se tornam fatores de diferenciação e inovação no ambiente dos negócios. Essa contradição consegue atingir o equilíbrio, no caso da indústria de sistemas integrados de gestão ou ERP (Enterprise Resources Planning), por meio da construção de valores que são sustentados pelos paradigmas da reputação e nos significados embutidos nas narrativas (histórias de implantação nas empresas dos sistemas de gestão, relatos de evolução e desempenho corporativo e mercadológico, relatos de fatos sobre novos produtos, novos investimentos, novos software, parcerias comerciais ou tecnológicas, premiações) de sua comunicação mercadológica e institucional.

O presente estudo analisa as novas relações de comunicação midiática presentes no discurso dos press-releases que incorporam as narrativas da empresa contemporâneas do setor de TI, representada na pesquisa pelas narrativas informacionais da empresa pioneira, globalmente, no segmento de sistema integrado de gestão empresarial ou ERP (Enterprise Resources Planning ou Planejamento dos Recursos Empresariais): a empresa que em na própria autoconceituação de sua identidade insere o objetivo-fim de sua tecnologia e da aplicação da mesma e da sua solução, a saber: "o ecossistema SAP oferece valor aos clientes que trabalham juntos para inovar e fornecer as melhores soluções", inserindo os valores que da economia informacional, interconectada e em rede (dois referenciais teóricos do presente estudo para levantamento dos indicadores de valor do discurso informativo da Comunicação Organizacional da empresa de sistema ERP.

Esses sistemas, surgidos inicialmente nos anos 1970, auxiliaram moldar o novo padrão da empresa contemporânea - que se sustenta no controle do fluxo da informação para todos os seus processos de relações com o mercado, com a sociedade, os agentes econômicos, sociais, governamentais, instituições - enfim, todos os stakeholders que compõem o ambiente do agente "empresa" no mundo atual.

Os fabricantes do ERP moldaram um discurso informativo que levou empresas dos mais diversos portes a adotarem suas tecnologias, nem sempre com sucesso. Mas foi esse discurso, embutido em suas narrativas de comunicação mercadológica e institucional, ao longo dos últimos anos, que lhes possibilitaram consolidar-se no mercado.

Estas narrativas disseminam a informação de que o caminho da competitividade, da eficiência, da alta produtividade de toda empresa contemporânea passa, inexoravelmente, pela adoção do produto (software ERP) e validadas pela retórica da experimentação, pela comprovação da reputação empresarial de suas marcas e de seus produtos narradas nas mensagens divulgadas.

A comunicação mercadológica/institucional das empresas de sistemas de gestão integrada (ERPs), principalmente as globais, como a SAP, valoriza as narra- 
tivas que tentam validar sua reputação e definir a aceitação de sua tecnologia, de modo a comprovar a receptividade das mesmas e o valor agregado disponibilizado pela empresa para os negócios em geral.

O conceito para reputação na indústria de software de Vendelo (1998) é um tipo de memória social e quando se "soma tudo, os múltiplos constituintes produzem uma gravura da imagem global da organização, atribuindo-lhe conceitos como excelente, bom, ruim, ou de dúvida; um valor embutido nas decisões feitas pelos clientes que passam a ter a partir dessa credibilidade e da boa vontade em suas decisões de escolha; disponibilidade em investir recursos para obter informação sobre as companhias e seus produtos ou a respeito de sua performance. Ao mesmo tempo, como a reputação tem um baixo custo de transação para o cliente, ela se torna, para estas companhias, um 'facilitador' das negociações comerciais" (VENDELO, 1998).

Para ele, a construção da reputação para esta indústria, "engaja um tipo de identidade, fazendo, com isto, tentativas para influenciar relevantes elementos dos seus ambientes de forma a colocar "a si mesma e seus produtos em um caminho particular. No contexto da indústria de software, quando ela aborda um novo mercado, ela irá produzir narrativas de sua performance futura com o fim de vender seus produtos para o cliente" (VENDELO, 1998, p. 4).

Assim, a aceitação por meio destas narrativas para o autor torna-se particularmente significativa tanto para as empresas de software quanto para companhias equivalentes - as chamadas empresas de conhecimento intensivo - que operam em mercados onde a pré-avaliação da qualidade de seus produtos é imprescindível.

"Estas companhias possuem enorme dificuldade em mensurar o valor da utilidade e da escolha por seu produto ou serviços, ambos sustentados na informação, no conhecimento embutido em seu bem. O desafio é fazer com que o mercado perceba o valor desse bem; o consumidor possa reconhecer as empresas que o produz como marca ou produto de qualidade, que sintam confiança no valor prometido, já que esse valor não pode ser materializado." (VENDELO, 1998, p. 1).

No setor de software, a dificuldade em se instaurar marcas ou tecnologias deriva do fato dos clientes não disporem de parâmetros de quantificação para sentirem ou dimensionarem o valor prévio, indicadores de qualidade de uma solução/software.

Para empresas de software, a reputação de sua marca, seus produtos e da empresa é obtida pela assimetria informativa com seus clientes no que diz respeito a seu expertise, o grau de usabilidade e capacidade de suas tecnologias e na geração de valor. Isto apenas demonstra que a maioria dos clientes são mal-informados sobre como mensurar a qualidade relativa das alternativas tecnológicas a serem consideradas e também encontram dificuldades para comparar e selecionar fornecedores. 
Para compensar a contradição existente os clientes destas empresas se utilizam da percepção que passam a dispor a respeito da qualidade dos produtos produzidos por elas, periodicamente, procurando indicadores da qualidade para os potenciais problemas que poderão ter ou não a partir da adoção de determinada tecnologia. Assim estão em constante processo de validação do grau de conhecimento detido por cada empresa (VENDELO, 1998, p. 10).

Nesse processo, a reputação e a comunicação inerentes à construção de sua identidade e marca, substituem a materialização do conhecimento, da expertise e da qualidade da tecnologia que cada companhia ou detém ou se esforça para ter dentro de um movimento de renovação, inovação e constante processo de validação por parte de seu usuário-cliente.

Ao mesmo tempo, "para conseguir tocar os clientes, influenciar suas expectativas e obter disponibilidade deles para ouvir seu discurso e argumentos, e convencê-los da sua própria capacidade, estas companhias devem dispor de excelente reputação para serem capazes de oferecerem a solução tecnológica demandada pela necessidade específica de cada cliente.” (VENDELO, 1998).

Os sistemas ERP, surgidos inicialmente nos anos 1970, moldaram um discurso que levou empresas (usuárias da tecnologia ERP) dos mais diversos portes a adotarem estes softwares nem sempre com sucesso. As narrativas destas empresas projetaram valores e ajudaram a disseminar os conceitos definidos pela nova economia dita informacional e em rede e validados por ações focadas na reputação. Como o insumo destas empresas é a informação, e já que suas narrativas embutem os próprios valores da economia informacional (CASTELLS, 2000), foi necessário transformar a comunicação na principal ferramental de sustentação do valor de seu bem, por meio de ações que pudessem comprovar a sua aceitação.

O instrumento de construção das narrativas informacionais, produzidas pela Comunicação Organizacional destas empresas, possibilitou disseminar modelos de negócios e ao mesmo tempo dar valor à sua tecnologia. Nestas narrativas percebe-se o uso intensivo dos chamados conceitos embutidos na corrente da economia informacional e em rede, que se tornaram indicadores de performance da economia contemporânea integrada em rede e globalizada, norteada por referenciais como inovação, integração, interligação, colaboração, entre outros, conforme demonstrado na pesquisa relatada a seguir.

\section{Método da pesquisa}

Cabe destacar que os aspectos da reputação e da construção de narrativas são temas que apenas nos últimos anos têm sido colocados na sociedade - uma demanda contemporânea das organizações para obterem valorização de mercado, de marca e respeito. É uma tendência surgida com o movimento de inte- 
gração financeira e dos mercados, pela exigência de sustentabilidade ambiental do planeta, por maior compromisso social por parte das empresas, fatores que levaram à adoção de novas posturas empresariais.

A presente pesquisa identificou, por um lado, em que medida o discurso das empresas contemporâneas dissemina os valores da reputação - por meio do estudo de caso da indústria que tem em seu produto a ferramenta que promete inovação para as mesmas. E ao mesmo tempo, como no objetivo inicial do projeto de pesquisa, se essas narrativas reproduziam os valores da economia informacional.

Para isso escolhemos o instrumento central de construção de narrativas baseadas na informação dos fatos comunicáveis: os press-releases institucionais e mercadológicos.

Nas narrativas mercadológicas - locais e globais - expandimos a análise para os testemunhais (cases) de clientes para verificar se os valores presentes nas narrativas globais e locais do discurso da marca se sintonizam com as expectativas das empresas usuárias ou compradoras do marca/sistema ERP.

Assim a pesquisa ora apresentada é dividida em:

- Narrativas institucionais e locais;

- Valores da marca - no institucional global e local;

- Presença dos indicadores de reputação - global e local;

- Narrativas mercadológicas locais e globais;

- Valores mercadológicos locais e globais;

- Expectativas dos clientes nos testemunhais locais e globais;

- Reputação reproduzida nos testemunhais locais e globais.

\section{Processos de análise}

Utilizando-se do processo estrutural, a pesquisa analisou a estrutura das narrativas e os significados embutidos para compreender seus valores e estratégias, focando a consolidação de suas tecnologias e da reputação das marcas em seus press-releases produzidos no segundo semestre de 2007 (agosto a dezembro), totalizando 116 textos, dividindo-os em duas partes: o institucional/ mercadológico, com o intuito de desmembrar o discurso corporativo (institucional) onde estão embutidos os indicadores de reputação corporativa com o intuito de levantar as narrativas das ações envolvendo regras de reputação como campanhas de sustentabilidade, compromisso social, responsabilidade financeira e governança corporativa. E o mercadológico/tecnológico, no qual foram encontrados os indicadores da economia informacional, como agregadores de valor de uso da tecnologia, nos cases produzidos: os testemunhais dos clientes. 
$\mathrm{Na}$ primeira etapa foram verificados os tempos verbais utilizados nos textos como forma de validar a hipótese da projeção de imagens de futuro, e de qualificação da marca e da tecnologia. Conforme Vendelo (1998): "usados como forma de apresentar sua performance futura e de materialização da sua capacidade de vislumbrar e linkar sua tecnologia" e que conforme reforça Charaudeau (2006): "demonstram o efeito de verdade, na busca pela credibilidade e reputação”.

Estes textos, cases/testemunhais, foram selecionados do site da empresa, tanto no Brasil quanto o global nos endereços: www.sap.com.br e www.sap.com. Relacionamos todos os títulos de cada texto, separando-os em cases/testemunhais, textos de fatos de parcerias, textos de tecnologias/produtos e textos de ações especificamente mercadológicas como participação em eventos, premiações, entre outros.

As narrativas foram relacionadas aos fatos institucionais, cujo discurso envolvia mensagens sobre os resultados globais, presentes tanto no site global (com), produzidos pelo centro da comunicação organizacional (Alemanha e Estados Unidos) e pelo local (com.br).

A análise seguiu os seguintes processos: determinação dos principais conceitos inerentes à economia informacional, em rede; determinação dos indicadores e conceitos de reputação inseridos em Argenti, Minguez e Vendelo (1998) numa sequência como a seguir: levantamento do local da produção, objetivando determinar no global o volume gerado do centro; quantidade reproduzida no local e, ao mesmo tempo, a proporção de produção dos discursos locais em relação ao global; levantamento dos verbos e seus tempos, objetivando ver a repetição dos mesmos em cada texto em relação aos conceitos de reputação e da economia informacional; comparativo, nos textos institucionais, da presença dos conceitos de reputação tanto no local quanto no global; comparativo nos textos mercadológicos da presença dos conceitos da economia informacional/ rede no local e global; e por fim, a identificação dos valores e os indicadores de reputação presentes no discurso institucional e mercadológico (local e global) da marca são percebidos pelo stakeholder cliente em seus testemunhais nos cases narrados pelo ERP.

Nesta última fase desenvolvemos a validação de nossas hipóteses, em que medidas as narrativas globais são reproduzidas no local e se elas focam os variados stakeholders do ambiente de relacionamento da empresa.

\section{Generalização dos resultados}

Pelo perfil do projeto proposto, foi utilizada amostragem intencional, determinada pelo tempo disponível para pesquisa e para manter a atualidade do fato em função dos textos disponíveis para o fechamento da mesma. 
Pela influência global da tecnologia do ERP, foi determinada como objeto a empresa SAP. Foi escolhida por seu pioneirismo e pela força de seu discurso global na disseminação da adoção da tecnologia do software ERP.

Determinou-se o instrumento de observação direta, pois se trabalhou com os recursos disponíveis e viáveis para a análise, tendo em vista a situação de um objeto em mutação, característica de seu universo de atuação, e que está inserido num momento histórico de mudança e inovação periódicas - assim como a característica do ineditismo da pesquisa.

\section{Modos de reputação na indústria de software}

Na pesquisa de Vendelo (1998), os principais referenciais de reputação da indústria de software e que colhemos nas narrativas são: relatos apresentando performance; relatos de afiliações, por meio da experiência direta com filiação/parcerias; de conhecimento sobre afiliações; de compromisso social, entre outros e reputação baseada em relatos de referenciais - cases baseados em experiência.

A reputação presente nas narrativas do software se baseia na construção dos chamados "fatos comunicáveis" (YANAZE, 2007) envolvendo a transmissão de conceitos de performance (reputação estruturada em experiência, no uso da tecnologia ou expectativas com esse uso), onde estão os cases/testemunhais. Estes narram ações que demonstram afiliações, pela experiência direta com as mesmas ou conhecimento acerca delas. Neste caso, inserimos as narrativas envolvendo colaboração, associações, esforços conjuntos e o compromisso social ou responsabilidade, cidadania ou conceitos correlatos. Nos capítulos 2 e 3 de Castells (2001) levantamos os principais conceitos de valor da economia informacional e que foram observados nas narrativas produzidas pelo ERP.

\section{Quadro I - Conceitos da Economia Informacional de Castells}

\begin{tabular}{l|l}
\hline Economia global & Mudanças organizacionais conexas \\
\hline $\begin{array}{l}\text { Capacidade de gerar; processar de forma eficiente } \\
\text { a informação e conhecimento }\end{array}$ & Maior eficiência \\
\hline $\begin{array}{l}\text { Escala global com capacidade de funcionar como unidade } \\
\text { em tempo real }\end{array}$ & Interação em redes empresariais \\
\hline Organização/agilidade em rede & Flexibilidade. Interação \\
\hline Agilidade em rede. Negócio em tempo real & $\begin{array}{l}\text { Tecnologias voltadas para o } \\
\text { gerenciamento }\end{array}$ \\
\hline
\end{tabular}




\begin{tabular}{|c|c|}
\hline Difusão a partir da tecnologia da informação & $\begin{array}{l}\text { Tecnologia de gerenciamento tecnológico } \\
\text { envolvendo mudanças organizacionais }\end{array}$ \\
\hline $\begin{array}{l}\text { Estratégia organizacional focada no cliente versus } \\
\text { estrutura organizacional descentralizada }\end{array}$ & Descentralização \\
\hline Processo de aprender fazendo & Auto-aprendizado \\
\hline Gastos com software pelo cálculo de produtividade & Investimento em software \\
\hline Aplicação da inovação através da tecnologia & $\begin{array}{l}\text { Tecnologia organizacional e de } \\
\text { gerenciamento - fatores que induzem } \\
\text { à produtividade e a produtividade } \\
\text { representa a riqueza das nações }\end{array}$ \\
\hline $\begin{array}{l}\text { As empresas não terão muita opção porque a } \\
\text { concorrência local e global, impondo regras e novas } \\
\text { tecnologias, eliminando os agentes econômicos } \\
\text { incapazes de obedecer às regras da economia }\end{array}$ & $\begin{array}{l}\text { Produtividade e a tecnologia são os } \\
\text { meios }\end{array}$ \\
\hline $\begin{array}{l}\text { As empresas estão motivadas pela lucratividade e maior } \\
\text { valor de suas ações }\end{array}$ & $\begin{array}{l}\text { Lucratividade e competitividade. } \\
\text { Determinantes da inovação tecnológica } \\
\text { e crescimento da produtividade }\end{array}$ \\
\hline Conquista/expansão de novos mercados & Redução de custos \\
\hline $\begin{array}{l}\text { Maior mobilidade, integração de mercado, maximizando } \\
\text { vantagens comparativas }\end{array}$ & Aceleração no giro do capital \\
\hline $\begin{array}{l}\text { Empresas dinâmicas, globais e de redes auxiliares - } \\
\text { empresas foram integradas ao novo sistema tecnológico }\end{array}$ & $\begin{array}{l}\text { Empresas globalizadas, integradas } \\
\text { em redes pela tecnologia }\end{array}$ \\
\hline Conhecimento/processos informacionais & $\begin{array}{l}\text { Elementos decisivos para o crescimento } \\
\text { econômico }\end{array}$ \\
\hline $\begin{array}{l}\text { Componentes estratégicos globais da economia, } \\
\text { centralizados com capacidade institucional, } \\
\text { organizacionável e tecnológicos de trabalho em unidades } \\
\text { e em tempo real. Em larga escala global }\end{array}$ & $\begin{array}{l}\text { Empresa em tempo real, integrada em } \\
\text { rede - global, interligada, controlada por } \\
\text { um ponto central e unidades distribuídas } \\
\text { em pontos no globo (em todos os níveis) }\end{array}$ \\
\hline Redes internas descentralizadas & Interação \\
\hline Redes de relações comerciais. Relacionamento. & $\begin{array}{l}\text { Organizações em unidades } \\
\text { semiautônomas }\end{array}$ \\
\hline
\end{tabular}

Nos conceitos de Castells (2001) - redes, eficácia, eficiência, produtividade, tempo real, integração - estão constantemente presentes nas narrativas do ERP. Nos conceitos da economia em rede definimos como valores fundamentais os referenciais presentes nos textos de Varian e Shapiro (2003), a saber: 


\section{Quadro II - Conceitos da economia em rede de Varian/Shapiro}

\begin{tabular}{l|l}
\hline Bem da experiência como bem da informação & Experimentação para atribuição de valor \\
\hline $\begin{array}{l}\text { A marca é um dos principais ativos e } \\
\text { instrumentos para construção de reputação }\end{array}$ & $\begin{array}{l}\text { Marca }=\text { como ativo que redunda } \\
\text { em reputação }\end{array}$ \\
\hline $\begin{array}{l}\text { Informação disponível de forma rápida, } \\
\text { disponível, disseminada e barata. } 0 \text { valor } \\
\text { verdadeiro produzido por um fornecedor de in- } \\
\text { formação reside em localizar, filtrar e comunicar } \\
\text { o que é útil para o consumidor }\end{array}$ & $\begin{array}{l}\text { Utilidade conforme a avaliação, a necessidade } \\
\text { definida pelo consumidor }\end{array}$ \\
\hline
\end{tabular}

A pesquisa a mostra em todas as narrativas a presença dos indicadores apontados em Castells (2001) e em Varian e Sharpiro (2003). No bem da experiência, a experimentação é a forma adotada para se atribuir valor. Para Vendelo (1998), narrar a experiência é o caminho para se obter reputação na indústria de software. Ao mesmo tempo, apontam os autores: investimento na marca é a estratégico como forma de perpetuar-se pela reputação. Nas narrativas desta indústria, a estrutura do discurso, por meio da marca, do nome da empresa, se torna fator de diferenciação e agregação de valor.

\section{Os resultados}

\section{As narrativas institucionais globais}

Percebeu-se pelo relato de fatos que a projeção da imagem de liderança nas narrativas globais é uma constante, demonstrando o crescimento contínuo. A validação tanto da marca, quanto de suas soluções tecnológicas e dos produtos e a sua conseqüente aceitação, são apontados nas narrativas e comprovados por meio de referenciais e premiações dados por entidades e institutos independentes com o intuito de demonstrar sua reputação. O discurso explora os indicadores de reputação, apontados por Minguez e Vendelo, junto ao stakeholder acionista, mostrando liderança de mercado, conforme alguns discursos: "empresa líder de análise de mercado comprova crescimento"; "SAP inserida no quadrante de liderança do mercado de portais"; "SAP ganha prestígio SSPA Star Award"; "SAP inserida no quadrante de líderes em utilities"; "Empresa independente coloca SAP na liderança dos mercados de ERP, CRM e SCM".

Nestas narrativas mantém-se a unicidade do discurso e um padrão estrutural de linguagem no relatar dos fatos, seguindo a lógica informativa, localizando a informação pela citação do tempo e do local geográfico, além da fonte da informação. O agente emissor, a empresa, sempre é o ator principal do discurso, com o uso de verbo na primeira pessoa do singular. Ela anuncia, no presente, 
mostrando a atualidade do fato, repassando a percepção do "acabou de acontecer", do hoje factualizado.

A expressão presente em toda narrativa tem início com o ator qualificado em suas ações por formas verbais como "tem reconhecido, tem obtido, tem posicionado, tem selecionado", complementado pelo infinitivo de alguns verbos como: gerar, tornar, gerenciar, permitir oferecer, declarar, reiterar, desenvolver, integrar, retificar, assegurar, padronizar, colocar, posicionar - a serem percebidos pelos vários stakeholders do "ecosistema" do ERP, ao mesmo tempo, em "dar aviso, tornar público, prognosticar" , mantendo a responsabilidade da ação sobre ela, o que lhe dá, de certa forma, o domínio sobre o fato e o processo a ser realizado, a ser concretizado pelas ações do provável receptor da mensagem. Com isso, a percepção que fica é de que o ator antecipa-se, apresentando inovação, pioneirismo, através do fato que a narrativa relata.

Esse discurso repete narrativas de ações que atendem ao compromisso corporativo com os públicos participantes do "ecosistema SAP” (a rede de negócios formada por clientes, integradores de tecnologia, desenvolvedores de tecnologia; vendors - fornecedores de soluções tecnológicas); clientes; imprensa; analistas setoriais; funcionários; parceiros (canal de distribuição local, regional e global); empresas de análises; acionistas e sociedade/comunidades locais com foco em responsabilidade e compromisso social ou cidadania.

As narrativas demonstram a aceitação, liderança, credibilidade, crescimento pelas aquisições, expansão em outras regiões do planeta e por pesquisas de analistas de mercado, que comprovem a liderança em determinados setores e nichos de mercado, além da confiança dos agentes de suas relações - institucionais e mercadológicas.

O discurso global de reputação da empresa de software ERP aponta valores como compromisso, vantagem competitiva sustentável e incremento de valor ao cliente.

A produção das narrativas institucionais, globais, não segue um cronograma fixo ao longo do período (seis meses), mas se nota que os discursos são elaborados em razão da urgência e da importância de determinadas ações para a imagem e consolidação da identidade corporativa da organização - com foco global. Assim, temas como "inserção da organização no quadrante de líderes globais do setor"; "prestígio por excelência de software"; "aquisição de empresas"; "decisões que impliquem em redução ou valorização do valor do capital"; "análises independentes que coloquem a marca em liderança ou amplie sua reputação global”; "anúncio de resultados preliminares ou anuais" - são conceituados no centro de decisão global e reproduzidos, localmente, no mesmo padrão e com a mesma mensagem original.

1 Análise que segue as conclusões do livro de Escribano (2001, p. 47). 
Ao mesmo tempo, narrativas institucionais globais são também construídas no que chamamos de subcentro - os Estados Unidos -, que tem o mesmo desempenho e valor para o capital equivalentes ao centro. Nesse caso, o discurso segue o mesmo padrão estrutural do centro, mas relata ações que integram o global, envolvendo temáticas como: "reconhecimento de liderança", "premiações continentais" (região das Américas), "crescimento e liderança regionais" e "reconhecimento a canais de distribuição e parcerias regionais". Estas narrativas nos remetem (reputação das narrativas de software no modelo de Vendelo), que aponta o reconhecimento como indicador de reputação na indústria do software. Por outro lado, o discurso global - da sede e do subcentro - interfaceia-se na construção de narrativas que demonstrem as estratégias corporativas globais da marca.

Tabela 1 - Valores do institucional global

\begin{tabular}{l|l|l}
\hline \multirow{2}{*}{ Importância } & Valor & $\begin{array}{c}\text { Número de } \\
\text { citações }\end{array}$ \\
\hline \multirow{2}{*}{$1^{\circ}$. lugar } & Inovação & 30 \\
\cline { 2 - 3 } & Co-inovação & 11 \\
\hline $2^{\circ}$. lugar & Liderança & 22 \\
\hline $3^{\circ}$. lugar & Global & 19 \\
\hline $4^{\circ}$ lugar & Colaboração & 12 \\
\hline $5^{\circ}$ lugar & Eficiência & 10 \\
\hline $6^{\circ}$ lugar & Flexibilidade. Crescimento. Integração & 9 cada \\
\hline $7^{\circ}$ lugar & Negócios em rede & 5 cada \\
\hline $8^{\circ}$ lugar & Parceria & 4 cada \\
\hline $9^{\circ}$ lugar & Funcionalidade. Otimização & 3 cada \\
\hline $10^{\circ}$ lugar & Governança. Escalabilidade & 2 cada \\
\hline $11^{\circ}$ lugar & $\begin{array}{l}\text { Redução da complexidade, padronização, redução dos custos, } \\
\text { maximização, produtividade, interação virtual, integração } \\
\text { em rede, excelência, competitividade, velocidade, reputação, } \\
\text { maximização do investimento, aceleração, performance, } \\
\text { escalabilidade global. }\end{array}$ & 1 cada \\
\hline
\end{tabular}

Amostra: 33 press-releases institucionais 
Tabela 2 - Ações com foco em reputação - global

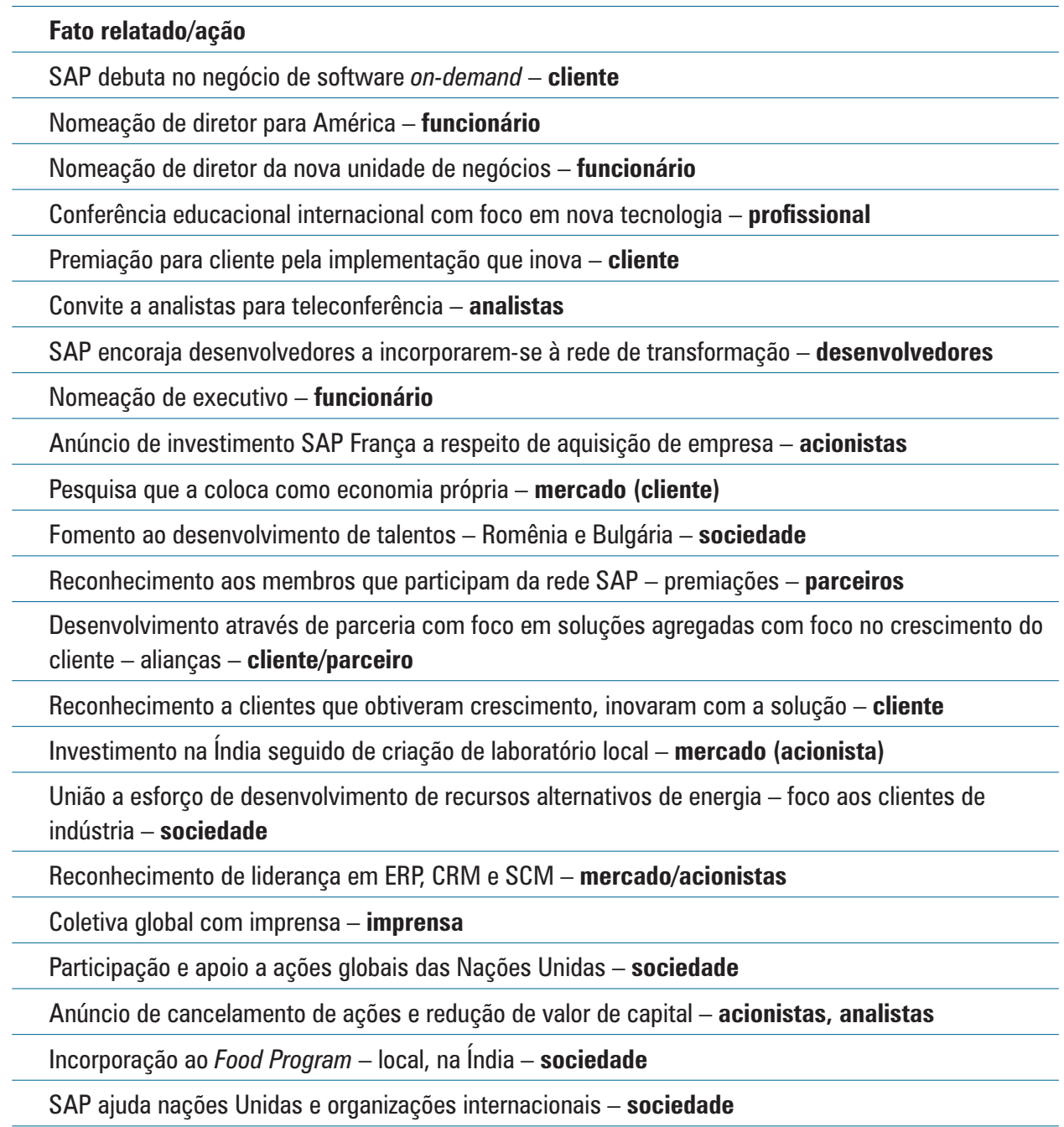

\section{0 institucional local}

Nas narrativas locais não se percebe, como nas narrativas institucionais globais, a mesma rigidez e inflexibilidade e padronização na forma do discurso. Os relatos não necessariamente demonstram atualidade, perdendo o referencial do processo midiático, como é proposto pela narrativa informativa do discurso da informação - tão presente no global.

O relato inicial do fato não acompanha, como no discurso global, o enunciado "anuncia hoje", mas o ator, agente da ação, continua sendo a marca. Enquanto no global há a padronização do ator (a SAP AG, mesmo que venha seguida 
de um subator), no local, o agente assume diversas identidades. A localização da informação, assim como o tempo e a fonte, são reproduzidos no local e se transformam no padrão informativo.

Interessante observar, nos fatos locais, forte vinculação das narrativas com a reputação social e com os valores que remetem à cidadania, compromisso social/sustentabilidade e reputação educacional, pela repetição de palavras cidadania, consciência social, sustentável - remetendo aos referenciais de reputação do local.

O valor inovação, que no discurso global é destacado, localmente perde importância em relação à liderança que assume lugar e destaque. Porém, os três principais valores globais (inovação, liderança e globalidade) recebem o mesmo grau de valor localmente, assim como aqueles relacionados mais à aplicabilidade da tecnologia como funcionalidade, colaboração, flexibilidade, funcionalidade e redução do custo.

Percebe-se a valorização dos fatos que indiquem reputação social e creditem a imagem de inovação da empresa e responsabilidade com o local, mantendo, porém, os conceitos de marca do discurso global como liderança, crescimento, global e aqueles que reforçam os da economia informacional, tais como redução de custos, colaboração, eficiência, disponibilidade, interação.

Tabela 3 - Valores embutidos nas narrativas institucionais do local

\begin{tabular}{l|l|l}
\hline Importância & Valor & $\begin{array}{l}\text { Número de citações } \\
\text { (total da amostra) }\end{array}$ \\
\hline $1^{0}$ lugar & Liderança & 7 \\
\hline $2^{0}$ lugar & Crescimento & 6 \\
\hline $3^{0}$ lugar & Global & 5 \\
\hline $4^{0}$ lugar & $\begin{array}{l}\text { Inovação } \\
\text { Consciência social }\end{array}$ & 4 cada um \\
\hline $5^{0}$ lugar & Parceria/aliança; tempo real; transformação & 3 cada um \\
\hline $6^{0}$ lugar & Redução de custo; colaboração & 2 \\
\hline $7^{0}$ lugar & $\begin{array}{l}\text { Eficiência, cidadania, performance, facilitadora, } \\
\text { otimização, disponibilidade, sustentabilidade, } \\
\text { competitividade, comunidade, integração }\end{array}$ & 1 \\
\hline
\end{tabular}

Amostra: 12 press-releases 
Tabela 4 - As narrativas de reputação institucional local

\begin{tabular}{l|l|l}
\hline Narrativas & Foco & Origem \\
\hline Educação - programa de certificação & $\begin{array}{l}\text { Integradores, parceiros, desen- } \\
\text { volvedores }\end{array}$ & global \\
\hline Programa de estágio & $\begin{array}{l}\text { Estudantes, universidades, } \\
\text { sociedade }\end{array}$ & local \\
\hline Programa de especialização & Acima & local \\
\hline Funcionários praticam cidadania & Interno e sociedade & local \\
\hline Integração programa Junior achievement & Sociedade & regional, local \\
\hline Programa consciência social & $\begin{array}{l}\text { Sociedade, clientes, governo, } \\
\text { universidade }\end{array}$ & local \\
\hline 400 empregos no Sul do país & Sociedade, governo & local \\
\hline
\end{tabular}

\section{As narrativas mercadológicas globais}

Os discursos mercadológicos globais estão em total sintonia com a identidade apontada no discurso institucional. A atualidade do discurso mercadológico implica em narrativas como ofertas de novas soluções e esforços de desenvolvimento tecnológico por meio de programas de parcerias; integração de stakeholders - parceiros e desenvolvedores; anúncios de novos produtos ou soluções, extensão de novos recursos e capacidades tecnológicas; eventos de apresentação de produtos, novas metodologias, arquiteturas de implantação ou programas de certificação em tecnologia.

No mesmo nível, as narrativas mercadológicas enfocam projeções de demandas e tendências futuras da tecnologia, que concernem às novas práticas e conceitos relacionados às inovações, redundando em melhorias para os clientes - via esforços colaborativos e de desenvolvimento entre membros da comunidade SAP e da chamada rede de inovação SAP (formada por desenvolvedores, consultores, arquitetos de software e especialistas em processos de negócios, clientes e parceiros de tecnologia). Como exemplo o estudo aponta o uso de verbos como "prover, demonstrar, acelerar, unir, implementar, oferecer, realizar, destacar, demonstrar, acelerar, promover, apresentar, consolidar, acelerar, propiciar, marcar, organizar, ampliar, combinar, reforçar.

O uso repetido de verbos como desenvolver, receber, incluir, contribuir, criar, validar, introduzir, denota a preocupação em qualificar, trazer para si a ação da inovação e coinovação, projetando a imagem de ator impulsionador dos fatos relatados remetendo à identidade reproduzida no institucional (local e global) - agregados ao valor integração. Um valor que, de certa forma, está embutido no objetivo-fim do produto (da tecnologia) ERP. 
Nos indicadores de reputação das narrativas mercadológicas globais percebese, claramente, o uso intensivo da linguagem técnico-informacional, expondo as reais intenções de valor mercadológico da marca: validação da qualidade, da aplicabilidade e dos benefícios das soluções ao negócio. A idéia é transmitir a noção de inovação em sua marca e a visão futurista (tecnológica). Essas intenções são percebidas por meio dos valores priorizados e repetidos nos textos (inovação, integração, colaboração, flexibilidade e rede como os mais valorizados) e nas ações de comunicação e de marketing relatadas nas narrativas.

É no discurso informativo mercadológico que a tecnologia está presente - nos títulos de cada narrativa; na valorização da linguagem técnico-informacional.

O ator de todo fato é sempre o agente ERP, a empresa que o representa. No local não há, tanto no institucional como no mercadológico, um padrão de identidade do sujeito das narrativas. Enquanto no global (tanto o institucional quanto o mercadológico) o ator é sempre a empresa, no local a identidade assume outros perfis: a SAP Brasil, a SAP ou a SAP AG.

Comparando os valores mercadológicos globais com os locais, inovação é o principal valor disseminado. Em contrapartida, enquanto no global integração fica em segundo lugar - em grau de importância; no local, crescimento e consolidação superam integração com margem de cerca de $30 \%$ para baixo em nível de valorização nas narrativas. Mas estes conceitos alinhados à liderança $\mathrm{e}$ aqueles relacionados à qualidade dada pelo ERP ao cliente, como flexibilidade, competitividade, redução de riscos / custos, disponibilidade, eficiência, visibilidade, otimização, interação, rapidez, aceleração e simplificação, são conceitos disseminados no mercado local.

Tabela 5 - Os valores mercadológicos do global

\begin{tabular}{l|l|c}
\hline Grau de importância & Valor & $\begin{array}{c}\text { Número de } \\
\text { citações }\end{array}$ \\
\hline $1^{\circ}$ lugar & Inovação. Coinovação & 24 e 9 \\
\hline $2^{\circ}$ lugar & Integração & 23 \\
\hline $3^{\circ}$ lugar & Flexibilidade & 22 \\
\hline $4^{\circ}$ lugar & Colaboração & 17 \\
\cline { 2 - 3 } & Rede & 14 de cada \\
\hline $5^{0}$ lugar & Rede de transformação & 11 \\
\hline $6^{0}$ lugar & Crescimento & 6 \\
\hline $7^{\circ}$ lugar & Global & 5 \\
\hline $8^{\circ}$ lugar & Aceleração & 4 \\
\hline
\end{tabular}




\begin{tabular}{l|l|c}
\hline $9^{\circ}$ lugar & $\begin{array}{l}\text { Transformação } \\
\text { Redução de custos } \\
\text { Inovação colaborativa }\end{array}$ & \\
\hline \multirow{2}{*}{$10^{\circ}$ lugar } & Eficiência; comunidade; interação; \\
& transparência; adaptabilidade; agilidade; \\
& performance; just-in-time; velocidade; & 1 de cada \\
& escalabilidade; alta performance; \\
& elasticidade; competitividade; rapidez; \\
& visibilidade; parceria; elasticidade; & \\
& governança, comunidade. & \\
\hline
\end{tabular}

Amostra: 23 press-releases

Tabela 6 - Os valores mercadológicos locais

\begin{tabular}{l|l|c}
\hline $\begin{array}{l}\text { Grau de } \\
\text { importância }\end{array}$ & Valor & $\begin{array}{c}\text { Número de } \\
\text { citações (total } \\
\text { da margem) }\end{array}$ \\
\hline $1^{\circ}$ lugar & Inovação & 20 \\
\hline $2^{\circ}$ lugar & Consolidação. Crescimento & 13 cada \\
\hline $3^{\circ}$ lugar & Integração & 10 \\
\hline $4^{\circ}$ lugar & Liderança. Global. Flexibilidade. Competitividade & 6 cada \\
\hline $5^{\circ}$ lugar & $\begin{array}{l}\text { Redução de riscos } \\
\text { Redução de custos }\end{array}$ & 5 cada \\
\hline $6^{\circ}$ lugar & Disponibilidade. Eficiência. Colaboração & 4 cada \\
\hline $7^{0}$ lugar & Funcionalidade. Aliança/Parceria. Rede/Conexão & 3 cada \\
\hline $8^{\circ}$ lugar & Visibilidade. Aceleração. Melhoras práticas & 2 cada \\
\hline $9^{\circ}$ lugar & Otimização, interação, rapidez, aceleração, simplificação & 1 cada \\
\hline
\end{tabular}

Amostra: 16 press-releases disponibilizados e disseminados no local (Brasil)

\section{As narrativas de percepção do cliente nos cases do mercadológico global}

No desenvolvimento das narrativas dos testemunhais dos clientes são relatadas as expectativas que incorporam alguns dos principais valores do mercadológico global, identificados com os da economia informacional. Dentre estes: eficiência, integridade, integração, flexibilidade, eficiência, inovação, otimização, melhores práticas, redução de riscos e de custos. Crescimento, transformação, confiabilidade, visibilidade, produtividade, real-time, controle, redução de custos, redução dos riscos, suporte. 
Em algumas narrativas destes cases notou-se a presença dos indicadores de reputação corporativa como fator de adoção da tecnologia na busca por reputação, compromisso, transparência, visibilidade no negócio.

Ao mesmo tempo, a pesquisa apontou a presença de algumas expectativas como: maior produtividade; mobilidade; maior eficiência nos serviços aos clientes; vantagem competitiva; controle de custos; melhores práticas da gestão; transformação das operações; reinvenção do negócio; incremento da eficiência; integração; visibilidade da informação; acesso centralizado; maior transparência; análise da performance; modernização da infraestrutura de negócio; continuidade da expansão; centralização da operação; processos mais produtivos; controle dos custos; colaboração entre empregados; processos eficientes. Estas se alinham com os valores disseminados pelo mercadológico global como integração, crescimento, eficiência, flexibilidade, global, transformação do negócio e otimização, com ganhos de produtividade.

No local, estas expectativas refletem as mesmas do global, adicionadas por relatos acerca de sustentabilidade, comprometimento, demonstrando uma surpreendente necessidade e especificidade local e que se integra à estratégia do discurso, principalmente, do institucional do ERP local.

As análises realizadas com relação aos testemunhais dos clientes necessitam ser ampliadas por meio de futura pesquisa com foco no receptor dessas narrativas e a sua percepção a respeito dos indicadores apontados no presente estudo.

Tabela 7 - 0s valores das narrativas dos cases dos clientes globais

\begin{tabular}{l|l|l}
\hline Grau de importância & Valor & $\begin{array}{l}\text { Número de } \\
\text { citações }\end{array}$ \\
\hline $1^{\circ}$ lugar & Integração & 25 \\
\hline $2^{\circ}$ lugar & Crescimento & 19 \\
\hline $3^{\circ}$ lugar & Eficiência & 13 \\
\hline $4^{\circ}$ lugar & Flexibilidade & 11 \\
\hline $5^{\circ}$ lugar & Global & 9 \\
\hline $6^{0}$ lugar & $\begin{array}{l}\text { Transformação } \\
\text { Otimização }\end{array}$ & 8 cada \\
\hline $7^{0}$ lugar & $\begin{array}{l}\text { Produtividade } \\
\text { Inovação }\end{array}$ & 6 \\
\hline $8^{\circ}$ lugar & $\begin{array}{l}\text { Liderança } \\
\text { Transparência }\end{array}$ & 5 cada \\
\hline $9^{\circ}$ lugar & $\begin{array}{l}\text { Competitividade } \\
\text { Redução de custos ao cliente }\end{array}$ \\
\hline
\end{tabular}




\begin{tabular}{c|l|c}
\hline $10^{\circ}$ lugar & $\begin{array}{l}\text { Real-time } \\
\text { Rapidez } \\
\text { AceleraçãolVisibilidade }\end{array}$ & 3 cada \\
\hline $11^{\circ}$ lugar & $\begin{array}{l}\text { Velocidade, colaboração, cooperação, } \\
\text { customização, performance, automação, } \\
\text { adaptabilidade }\end{array}$ & 2 cada \\
\hline Outros & $\begin{array}{l}\text { Funcionalidade, foco, conectividade, } \\
\text { descentralização, escalabilidade, } \\
\text { competitividade, padronização, } \\
\text { customização, sucesso }\end{array}$ & 1 cada \\
\hline
\end{tabular}

Amostra: 19 press-releases

Tabela 8 - Valores presentes nas expectativas dos clientes nas narrativas dos cases locais

\begin{tabular}{|c|c|c|}
\hline $\begin{array}{l}\text { Grau de } \\
\text { importância }\end{array}$ & Valor & $\begin{array}{l}\text { Número de } \\
\text { citações }\end{array}$ \\
\hline $1^{\circ}$ lugar & Integração & 17 \\
\hline $2^{\circ}$ lugar & $\begin{array}{l}\text { Flexibilidade } \\
\text { Produtividade }\end{array}$ & 7 cada \\
\hline $3^{\circ}$ lugar & Crescimento & 6 \\
\hline $4^{0}$ lugar & Automatização & 5 \\
\hline $5^{0}$ lugar & $\begin{array}{l}\text { Conectividade } \\
\text { Confiabilidade } \\
\text { Otimização } \\
\text { Funcionalidade }\end{array}$ & 4 cada \\
\hline $6^{0}$ lugar & $\begin{array}{l}\text { Controle } \\
\text { Inovação } \\
\text { Liderança } \\
\text { Global } \\
\text { Aderência } \\
\text { Padronização } \\
\text { Colaboração }\end{array}$ & 3 de cada \\
\hline $7^{0}$ lugar & $\begin{array}{l}\text { Sustentabilidade, adaptação, agilidade, eficiência, } \\
\text { comprometimento }\end{array}$ & 2 de cada \\
\hline Outros & $\begin{array}{l}\text { Acesso remoto, descentralização, funcionalidade, } \\
\text { interação, reconhecimento, harmonização/sintonia, } \\
\text { competitividade, mobilidade, qualidade, velocidade, } \\
\text { consistência, reestruturação, adaptação, colaboração, } \\
\text { padronização, otimização }\end{array}$ & \\
\hline
\end{tabular}




\section{Considerações finais}

As narrativas globais da Comunicação Organizacional focalizam a reputação corporativa e preocupam-se em manter a unicidade do discurso, por meio da sua atualidade, do fato na disseminação dos valores, que estão intimamente relacionados com os dogmas da economia informacional.

Ao mesmo tempo em que se percebe a disseminação dos valores informacionais, as narrativas demonstram a importância da reputação para a marca como forma de manter unida a rede de colaboração da marca. Nessa rede, os atores são os principais stakeholders da relação colaborativa, todos identificados nas narrativas como "parceiros".

Todas as conclusões apresentadas pelo estudo de Vendelo (1998) foram validadas. Na premissa básica de seu estudo, ele demonstra que as narrativas de reputação da empresa de software são o instrumento estratégico para sua validação. Também é válida a aceitação do valor de uso do seu bem, o software, - presente no discurso informativo da comunicação. Para ela, é imprescindível o investimento na reputação com ações geradas pela Comunicação Organizacional.

Ao mesmo tempo em que se percebe a preocupação em validar a confiabilidade, impõe-se um perfil de negócio a ser buscado por toda empresa contemporânea, no que concerne à eficiência empresarial, à performance, à competitividade do negócio e, principalmente, à inovação. Esta característica, fortemente incorporada global e localmente à identidade da marca, aparece muito marcada em todas as narrativas da empresa de ERP.

O conceito inovação, informacional de Castells (2001) e de rede de Varian e Shapiro (2003), aparece nas narrativas, sendo o mais citado, o que demonstra a importância deste indicador para a empresa de software ERP. O discurso produzido é voltado para o global e o caminho apontado pelas narrativas é a atuação global em rede, com a inserção na rede de colaboração do ERP.

O ERP trabalha, como apontado no estudo de Vendelo (1998), na criação de narrativas por histórias de aplicação, em que demonstra os benefícios obtidos pela empresa-usuária que adota a tecnologia do ERP - os chamados cases. Nestas histórias consolidam-se o discurso do modelo de identidade da empresa "privilegiada" que adota a sua tecnologia. Esse discurso está em consonância integral com os dogmas da economia informacional e em rede; conceitos como performance, colaboração, eficiência e redução de custo como valores agregadores da adoção da tecnologia estão presentes tanto nas narrativas locais quanto globais.

Nos discursos elaborados pelo ERP, o formato informacional adotado incorpora os indicadores de reputação, principalmente no seu discurso institucional, 
buscando o diferencial competitivo, por meio da credibilidade e da imagem projetada de excelência - nomeados pelas ações de reputação relatadas nas narrativas, em suas falas e depoimentos, servindo para validar as afirmativas, estas proferidas por representantes oficiais da empresa.

No discurso global, situam-se o local e o tempo. Nestes também estão aquelas regiões onde circulam interesses estratégicos da organização, sejam eles comerciais, mercadológicos ou outros. Contudo o estudo não pode comprovar isso por não ter definido, na pesquisa, entrevistas com a organização, e, sim, ter centrado apenas na análise das narrativas informativas dos press-releases.

Com rigor e método, já que toda narrativa segue um padrão linguístico, uma forma do dizer bastante estruturada, o discurso obedece a um cronograma bem definido, dando valor tanto para os fatos mercadológicos - tecnologia, produto - quanto a fatos institucionais, tendo como alvo todos os stakeholders da "rede". Nas narrativas, todos os agentes da rede são contemplados, a notar a preocupação em integrá-los. Nelas, a preocupação em passar a importância da integração, da troca, do fazer, do relacionar-se em rede é bem presente. Afiliações e referenciais são fatores essenciais na construção das narrativas das reputações da indústria de software (VENDELO, 1998).

Os fatos comunicados no formato informacional global são reproduzidos no local apenas nos casos em que a informação implica em confirmação da reputação da marca no local.

Os conceitos de reputação do global se destacam na medida do mercado. Mas, no institucional, eles se recriam com conceitos diferenciados. No Brasil, sustentabilidade, responsabilidade social e cidadania são conceitos valorizados de reputação presentes nos fatos narrados, redundando em ações de comunicação especificas do país.

Ao mesmo tempo em que procura disseminar nas narrativas o modelo de identidade do negócio informacional em rede, o ERP inova, incorporando novos valores ao seu discurso. Os conceitos do ERP evoluíram aquém daqueles da economia informacional de Castells (2001). O discurso do ERP superou a fase da integração e parte para a inovação, formando sua própria economia em seu ecossistema tecnológico, com foco na inovação colaborativa, sustentável em sua própria rede.

\section{Referências}

ALBAGLI, Sarita; LASTRES, Helena M. M. (Orgs.). Informação e globalização na era do conhecimento. Rio de Janeiro: Editora Campus, 1999.

CASTELLS, Manuel. A sociedade em rede. 5. ed. São Paulo: Editora Paz e Terra, 2001.

CHARAUDEAU, Patrick. Discurso das mídias. São Paulo: Editora Contexto, 2006. 
ESCRIBANO, Asunción. Pragmática e ideología en las informaciones sobre conflictos políticos. Salamanca (Espanha): Publicaciones Universidad Pontificia de Salamanca, 2001

GORZ, André. 0 imaterial, conhecimento, valor e capital. 3. ed. São Paulo: Annablume, 2007.

IANNI, Octávio. A sociedade global. 10. ed. Rio de Janeiro: Civilização brasileira, 2002.

KOTLER, Philip. Administração de Marketing. São Paulo: Prentice Hall, 2000.

KUNSCH, Margarida Maria Kohling. Planejamento de relações públicas na comunicação integrada. 4. ed. São Paulo: Summus Editorial, 2003.

(Org.). Obtendo resultados com relações públicas. São Paulo: ECA-USP / Editora Pioneira, 1999.

LAUDON, Kenneth Craig; LAUDON, Jane Price. Sistemas de informação gerenciais. 7. ed. Tradução Thelma Guimarães. São Paulo: Pearson / Prentice Hall, 2007.

MATTELART, Armand. A globalização da comunicação. 2. ed. Bauru: Edusc, 2002.

ORTIZ, Renato. Mundialização e cultura. São Paulo: Editora Brasiliense, 1994.

RICCIO, Édson Luiz. Efeitos da tecnologia da informação na contabilidade: estudos de casos de implementação de sistemas empresariais integrados - ERP. Tese (Livre-docência em Contabilidade e Atuária) - Departamento Contabilidade e Atuária da Faculdade de Economia, Administração e Contabilidade. São Paulo: Universidade de São Paulo, 2001.

SANTOS, Milton. Técnica, espaço e tempo. 4. ed. São Paulo: Editora Hucitec, 1998.

. Território, globalização e fragmentação. 3. ed. São Paulo: Editora Hucitec, 1996.

VARIAN, Hal R. Economics of information technology. Berkeley: University of California, 2003.

VARIAN, Hal R; SHAPIRO, Carl. A economia em rede, como os princípios econômicos se aplicam à era da Internet. 8. ed. Rio de Janeiro: Elsevier / Editora Campus, 2003.

VENDELO, Morten Thanning. Narrating Corporate Reputation, becoming legitimate through storytelling. International Studies of Management \& Organization, Estados Unidos, v. 28, n. 3, p. 120-137, fall 1998.

YANAZE, Mitsuro Higuchi. Gestão de marketing e comunicação: avanços e aplicações. São Paulo: Editora Saraiva, 2007.

YUNGWOOK, Kim. Measuring the economic value of public relations. Journal of Public Relations Research, Estados Unidos, v. 13, n. 1, p. 3-26, 2001. 